\title{
SISTEMA DE ILUMINAÇÃO A LED ALIMENTADO POR PAINÉIS FOTOVOLTAICOS EM ÁREAS VULNERÁVEIS.
}

\author{
Lavínia Almeida- lavinia.almeida@alunos.unis.edu.br \\ Lucas Trindade - lucas.pereira6@alunos.unis.edu.br \\ Tiago Bittencourt-tiago.nazare@professor.unis.edu.br
}

\section{Resumo}

Este estudo analisa os benefícios que podem ser obtidos através de uma iluminação em diversos lugares e sendo assim, conseguindo verificar redução na atividade criminosa. Entre os benefícios verificados, temos a melhoria na saúde e ao acesso informação. A criminalidade, trata-se de um dos temas primordiais dos brasileiros e, embora existam esforços para reduzi-lo, eles continuam altos. Com isso, a deia central consiste em que a ampliação do acesso de iluminação pode oferecer uma forma de redução na criminalidade e pode ser vinculada a outras formas já existentes de combater o crime.

A utilização eficiente da energia elétrica é um tema que vem crescendo muito. No Brasil isso se deve principalmente àfalta de chuvas que impacta diretamente as usinas hidrelétricas que são a maior fonte de eletricidade no país. Este trabalho estuda maneiras de reduzir o consumo de energia elétrica dos sistemas de iluminação através da utilização de equipamentos mais modernos e eficientes. Nos últimos anos os diodos emissores de luz (LED's) vem revolucionando o setor de iluminação possibilitando a redução do consumo de energia com ótimos níveis de iluminação.

Palavras-Chaves: Sistema fotovoltaico, Segurança e Lâmpadas de LED.

\section{Introdução}

A importância da implementação de energia renováveis vem sendo um dos grandes fatores com a grande preocupação ao meio ambiente. O Brasil tem diversas fontes de geração limpa, mas a energia solar se destaca devido a sua disponibilidade e o seu potencial de transformação em energia térmica, 
utilizando sistema de painéis fotovoltaicos a ser convertida em energia elétrica. Com isso, eliminando completamente perdas.

A energia gasta anualmente com setor público de iluminação é de 15.443 GWh e representa $3,3 \%$ do consumo energético brasileiro (EMPRESA DE PESQUISA ENERGÉTICA, 2018), e por isso, mesmo uma pequena otimização, que reduza percentualmente este consumo pode causar um grande impacto. A solução proposta neste trabalho visa reduzir o consumo energético e intensidade da iluminação em momentos nos quais não há presença de pessoas próximas, otimizando o uso desse recurso.Para diminuir o consumo de energia da iluminação, a intensidade de luz emitida de luminárias pode ser diminuída conforme a presença humana, através de um sensor baseado em inteligência artificial e uma rede de comunicação das luminárias. Como a iluminação pública é de suma importância para os usuários da via, pois ela proporciona visibilidade e segurança, portanto, o controle que não retire esses benefícios é um desafio.

A criminalidade é um dos maiores problemas sociais no Brasil. Por ter informações colhidas por um órgão separado da gestão de policiamento, os dados obtidos tendem a apresentar melhor confiabilidade. Soares (2004) destaca as dificuldades e a importância de obter uma base de dados confiável na mensuração de impactos sobre criminalidade.

\section{Objetivos}

Um dos objetivos desse trabalho é mostrar o caminho para a realização de um projeto de eficiência em iluminação LED e apresentar a importância do estudo de viabilidade econômica. Apesar de estarmos sempre atualizados, com produtos de última geração, nem sempre conseguiremos economizar com eles. Sendo assim, é importante realizar o cálculo, para saber se o tempo de retorno é válido: ao realizar um estudo para saber quais lâmpadas devem ser trocadas,

por exemplo, conclui-se que as lâmpadas mais utilizadas representam uma contribuição maior no orçamento final. 


\section{METODOLOGIA}

Para desenvolvimento do projeto, foi realizada uma pesquisa no mês de abril de 2021, utilizando o método de pesquisa "Revisão de Literatura". Para isso se fez necessário, utilizar análises em livros, artigos acadêmicos e o uso da norma brasileira ABNT NBR 5101 do ano de 2018, dessa maneira tivemos potencial de realizar um projeto no sistema software dialux e visualizamos um checklist aonde nele constava todos os itens do projeto e assim verificamos se a ideia estaria dentro dos padrões de todas as normas e consequentemente alcançamos uma melhor compreensão da proposta do estudo. As normas seguidas foram ABNT NBR 5101 e NDU 035 da energisa que se trata de iluminação pública. Tendo como resultado, uma implantação de sistema de iluminação de em áreas que não possuem acesso esse tipo de serviço. Visando o conforto, segurança e qualidade de vida dos moradores.

Dentre as fontes renováveis, destaca-se neste trabalho a energia proveniente do Sol, que, por meio do efeito fotovoltaico, transforma energia solar em energia elétrica através de um sistema gerador de energia solar, que engloba os painéis, bem como os componentes adicionais, como inversores, baterias e controladores. (LIMA et al., 2020).

\section{Normas Utilizadas}

- NDU 035 - Iluminação Pública.

- NDU 001 - Fornecimento de energia elétrica a edificações individuais ou agrupadas até 3 unidades consumidoras.

- ETU 150 - Haste de aterramento de aço cobreado e acessórios.

- ABNT 5101 - lluminação Pública.

\section{Referencial Teórico}

\subsection{Radiação solar}

Após adentrar na atmosfera terrestre, devido à reflexão e absorção dos raios solares pela própria atmosfera, apenas uma parte dos raios solares atinge a superfície terrestre devido aos processos de reflexão e absorção, sofrendo uma certa redução na intensidade da radiação. A radiação eletromagnética interage 
distintamente com cada componente da atmosfera de acordo com 0 comprimento de onda da radiação (PEREIRA et al, 2017).

O processo físico de espalhar a radiação solar é produzido por moléculas de gás e partículas suspensas na atmosfera, além do espalhamento por bordas de nuvens ou efeito lente causados pela geometria Sol/Nuvens/Terra. Já a absorção acontece devido à presença de moléculas de ozônio (O3) que absorvem radiação solar em comprimentos de onda na faixa do ultravioleta e reduzindo a incidência na superfície; vapor de água com grande capacidade de absorver a radiação no infravermelho, mas que apresenta alta variação espacial e temporal na atmosfera (Yamasoe e Correa, 2016); oxigênio (O2) e dióxido de carbono (CO2), sendo este último responsável por absorver também radiação nos comprimentos de onda da região do infravermelho, retendo calor do sistema Terra-Atmosfera que seria perdida para o espaço (efeito estufa) (PEREIRA et al, 2017).

Aerossóis atmosféricos são partículas sólidas ou líquidas em suspensão na atmosfera. Podem ter origem natural ou antrópica e participam do processo de espalhamento da radiação solar. Tem-se ainda os aerossóis com grande influência no clima, pois aumentam a quantidade de radiação refletida no espaço (efeito albedo), e ainda atuam como núcleos formadores de gotículas de água provocando a formação de nuvens o que ajuda a remitir a radiação infravermelha na troposfera (Rafael Haag; Arno Krenzinger, 2010).

\section{Painel fotovoltaico}

O painel fotovoltaico e um dispositivo capaz de realizar a conversão de energia luminosa em energia elétrica, são compostas por pequenas unidades ou módulos denominados células fotovoltaicas. Cada célula fotovoltaica gera em média $0,5 \mathrm{~V}$, as disposições das ligações e o tamanho das células fornecem os níveis de tensão e corrente projetadas pelo fabricante. (Solarterra) A Figura 1 ilustra o painel fotovoltaico, e a estrutura básica de uma célula fotovoltaica. 
Figura 1 - a)Painel Fotovoltaica b)Estrutura Célula Fotovoltaica

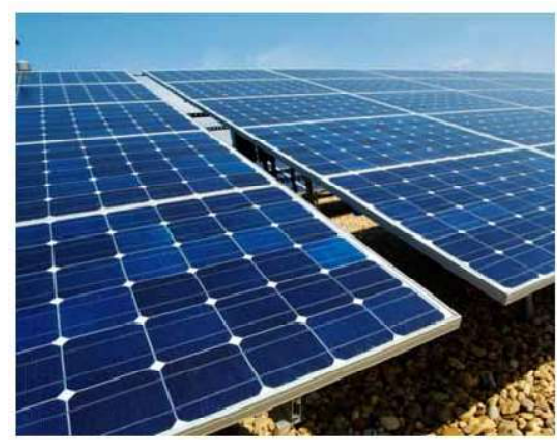

(a)

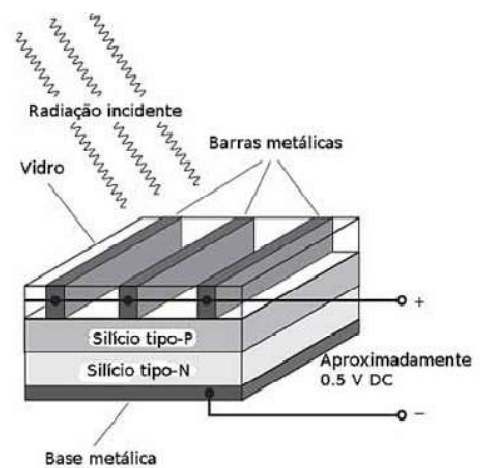

(b)

Fonte: (Portal Solar, 2009)

Os painéis fotovoltaicos podem ser empregados em sistemas de micro geração, podendo ser classificados como sistemas conectados à rede, quando se encontram conectadas a rede da distribuidora de energia, fornecendo parte ou excedente da energia gerada ou podem ser classificados como sistemas autônomos, quando o sistema se encontra conectado a uma rede particular, sendo necessário o armazenamento de energia em baterias para uso posterior. A energia produzida através de painéis fotovoltaicos e considerada uma fonte de energia limpa por não gerar nenhum resíduo durante processo de geração de energia. Podem ser instalados em locais diversos, devido ao seu formato compacto e a facilidade de montagem de seus módulos.

\subsubsection{Células Fotovoltaicas}

As células fotovoltaicas são unidades básicas de conversão da energia solar em energia elétrica por meio do efeito fotovoltaico. Por definição, o fenômeno da geração de um fluxo de elétrons resultante da incisão de feixes de radiação do sol sobre a superfície da placa fotovoltaica é chamado de efeito fotovoltaico. Esse efeito ocorre em materiais semicondutores, essenciais na produção das células fotovoltaicas, que apresentam características condutivas intermediárias entre os metais e ametais e cuja condutividade varia com a temperatura, sendo amplamente utilizados na fabricação de componentes eletrônicos (SAMPAIO et al., 2019).

Há mais de meio século as tecnologias de geração de energia solar fotovoltaica são pesquisadas e desenvolvidas com o intuito de trazer para o mercado 
células cada vez mais eficientes, de custo reduzido e com potencial para se tornarem alternativas viáveis e acessíveis às fontes já existentes. Nos últimos anos, o principal fator impulsionador das pesquisas é a eficiência de conversão, que se refere à quantidade de energia elétrica que uma célula fotovoltaica é capaz de gerar por $1 \mathrm{~m}^{2}$ em 1 hora de funcionamento em condições de laboratório (LIMA et al., 2020). O aumento da eficiência das células fotovoltaicas é fundamental para diminuição dos custos de fabricação dos módulos, gerando um mercado competitivo.

\subsubsection{Silício Monocristalino}

O silício monocristalino geralmente é fabricado pelo processo Czochralski, cujo produto final é cortado em lâminas de 0,3 $\mathrm{mm}$ de espessura aproximadamente, com as quais se produzem as células fotovoltaicas. Esse processo se baseia no crescimento do cristal a partir do silício policristalino fundido a $1500^{\circ} \mathrm{C}$, no qual é adicionado, por meio de uma haste, uma semente de silício monocristalino. Nesta semente estão presentes todas as características que o lingote apresentará após o processo de cristalização, obtendo a mesma orientação cristalográfica da semente (SAMPAIO et al., 2019). Outro processo produtivo utilizado na indústria de fabricação das células de silício monocristalino é o de Float-Zone. De forma geral, este processo consiste em fundir uma região de uma barra de silício policristalino por aquecimento indutivo e deslocar, lentamente, o foco de calor ao longo da barra que se movimenta em rotação e translação, no qual um cristal de semente é usado em uma extremidade, a fim de iniciar o crescimento do silício monocristalino (SAMPAIO et al., 2019).

Essas células apresentam altos custos de fabricação, maior tempo de retorno de energia, requerem uso de materiais muito puros (silício de grau solar) e demandam maior quantidade de energia durante sua fabricação devido ao seu processo produtivo, com relação aos outros tipos de células. Esta tecnologia apresenta uma eficiência máxima de $23 \%$, tempo de vida útil de 25 a 30 anos (IRENA, 2012) e, segundo o site HomeAdvisor (2020), tem um custo máximo do sistema (incluindo acessórios operacionais como inversores, conectores, fiação entre outros) de US \$ 1 a US \$1,50 por Watt. 
Figura 2 - a) Painel Fotovoltaico Si-Monocristalino b)Estrutura Si-Monocristalino

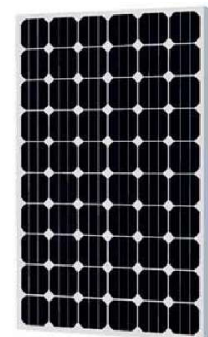

(a)

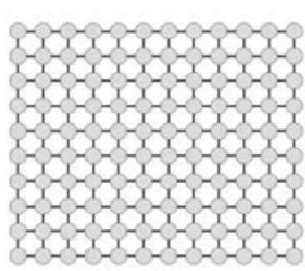

(b)

Fonte: (Portal Solar, 2009)

\section{Lâmpadas de LED}

As atuais lâmpadas de LED são até $50 \%$ mais econômicas e a qualidade da iluminação é superior à das lâmpadas de vapor de sódio (AGUERA, 2015), além de ser possível controlar sua intensidade luminosa e de não ser preciso aguardar o tempo de religamento, ou seja, a lâmpada pode ser desligada e ligada novamente sem que haja um período de espera. Em outras palavras, lâmpadas de LED são mais controláveis do que lâmpadas de vapor metálico, isso abre novas possibilidades tecnológicas.

As lâmpadas de LED, além de serem mais eficientes que as demais, não possuem metais ou gazes poluentes e tóxicos. Outra vantagem é que o feixe de luz não contém raios infravermelhos, ou seja, não emite uma onda de luz invisível ao olho humano e que gera calor. Lâmpadas de LED não precisam de altas e constantes tensões, ao contrário, elas funcionam em uma ampla faixa de tensão, reduzindo seu brilho caso recebam tensões abaixo do seu valor nominal, além de ter a maior vida útil entre todos os tipos de lâmpada (LIMA, 2018).

De acordo com Dallabrida, Gonçalves e Piovesan (2015), a lâmpada incandescente emite $742,85 \%$ mais calor do que a lâmpada de LED, além de a lâmpada de LED ter a maior vida útil entre as lâmpadas apresentadas, com cerca de 30.000 horas de trabalho, enquanto a fluorescente e a incandescente ficam com 6.000 e 1.000 horas, respectivamente. Sua eficiência também é a mais alta, $88 \%$. 


\section{Norma Utilizada para Montagem no Projeto no Dialux}

Quadro 1 e 2, Defina-se a classe de iluminação para cada tipo de via tráfego de veículos, iluminância média mínina e uniformidade para cada classe de iluminação, vias para tráfego de padestre.

\begin{tabular}{|l|c|}
\hline \multicolumn{1}{|c|}{ Descrição da via } & $\begin{array}{c}\text { Classe de } \\
\text { iluminação }\end{array}$ \\
\hline $\begin{array}{l}\text { Vias de trânsito rápido; vias de alta velociclade de tráfego, com separação de pistas, sem } \\
\text { cruzamentos em nivel e com controle de acesso; vias de trânsito rápido em geral; Auto- } \\
\text { estradas }\end{array}$ & V1 \\
Volume de tráfego intenso & V2 \\
Volume de tráfego médio & \\
\hline
\end{tabular}

\section{Quadro 1}

Fonte: (ABNT NBR 5101, 2018)

Quadro 2,Defina-se a classe de iluminação para cada tipo de via tráfego de veículos, iluminância média mínina e uniformidade para cada classe de iluminação, vias para tráfego de padestre.

\begin{tabular}{|l|c|}
\hline \multicolumn{1}{|c|}{ Descrição da via } & $\begin{array}{c}\text { Classe de } \\
\text { iluminação }\end{array}$ \\
\hline $\begin{array}{l}\text { Vias arteriais; vias de alta velocidade de tráfego com separação de pistas; vias de mão } \\
\text { dupla, com cruzamentos e travessias de pedestres eventuais em pontos bem definidos; vias } \\
\text { rurais de mão dupla com separaçāo por canteiro ou obstáculo } \\
\text { Volume de tráfego intenso }\end{array}$ & \\
Volume de tráfego médio & V1 \\
\hline Vias coletoras; vias de tráfego importante; vias radiais e urbanas de interligação entre & V2 \\
bairros, com tráfego de pedestres elevado & \\
Volume de tráfego intenso & V2 \\
Volume de tráfego médio & V3 \\
Volume de tráfego leve & V4 \\
\hline Vias locais; vias de conexão menos importante; vias de acesso residencial & V4 \\
Volume de tráfego médio & V5 \\
Volume de tráfego leve & \\
\hline
\end{tabular}

Quadro 2

Fonte: (ABNT NBR 5101, 2018).

No Quadro 3,Defina-se ailuminação média e fator de uniformidade mínimo para cada classe de iluminação. 


\begin{tabular}{|c|c|c|}
\hline $\begin{array}{c}\text { Classe de } \\
\text { iluminação }\end{array}$ & $\begin{array}{c}\text { Iluminância média minima } E_{\text {med,min }} \\
\text { lux }\end{array}$ & $\begin{array}{c}\text { Fator de uniformidade minimo } \\
U=E_{\text {minn }} / E_{\text {med }}\end{array}$ \\
\hline V1 & 30 & 0,4 \\
\hline V2 & 20 & 0,3 \\
\hline V3 & 15 & 0,2 \\
\hline V4 & 10 & 0.2 \\
\hline V5 & 5 & 0,2 \\
\hline
\end{tabular}

Quadro 3

Fonte: (ABNT NBR 5101, 2018).

Quadro 4, defina-se a classe de iluminação para cada tipo de via para tráfego de pedestres.

\begin{tabular}{|l|c|}
\hline \multicolumn{1}{|c|}{ Descriçāo da via } & Classe de iluminação \\
\hline $\begin{array}{l}\text { Vias de uso noturno intenso por pedestres (por exemplo, calçadöes, passeios } \\
\text { de zonas comerciais) }\end{array}$ & P1 \\
\hline $\begin{array}{l}\text { Vias de grande tráfogo noturno de pedestres (por exemplo, passeios de } \\
\text { avenidas, praças, àreas de lazer) }\end{array}$ & P2 \\
\hline $\begin{array}{l}\text { Vias de uso noturno moderado por pedestres (por exemplo, passeios, } \\
\text { acostamentos) }\end{array}$ & P3 \\
\hline $\begin{array}{l}\text { Vias de pouco uso por pedestres (por exemplo, passeios de bairros } \\
\text { residenciais) }\end{array}$ & P4 \\
\hline
\end{tabular}

Quadro 4

Fonte: (ABNT NBR 5101, 2018).

Quadro 5, defina-se iluminância média e fator de uniformidade mínimo para classe de iluminação.

\begin{tabular}{|c|c|c|}
\hline $\begin{array}{c}\text { Classe de } \\
\text { iluminação }\end{array}$ & $\begin{array}{c}\text { Iluminância horizontal média } E_{\text {med }} \\
\text { lux }\end{array}$ & $\begin{array}{c}\text { Fator de uniformidade mínimo } \\
U=E_{\text {min }} / E_{\operatorname{med}}\end{array}$ \\
\hline P1 & 20 & 0,3 \\
\hline P2 & 10 & 0,25 \\
\hline P3 & 5 & 0,2 \\
\hline P4 & 3 & 0,2 \\
\hline
\end{tabular}

Quadro 5

Fonte: (ABNT NBR 5101, 2018) 


\section{Resultados}

O local de implementação dessa ideia esta localizada em um loteamento de chácaras podemos veririfar todas as fases necessárias para essa execução e controle do projeto. Com o detalhamento de cada fase verificamos que o objetivo foi atendido, pois quando fizemos a ideia do projeto no Dialux ele atendeu todas as normas exigidas para a implementação da iluminação pública.

Figura 1, é o local de implementação do projeto, aonde está localizada em um loteamento de chácara.

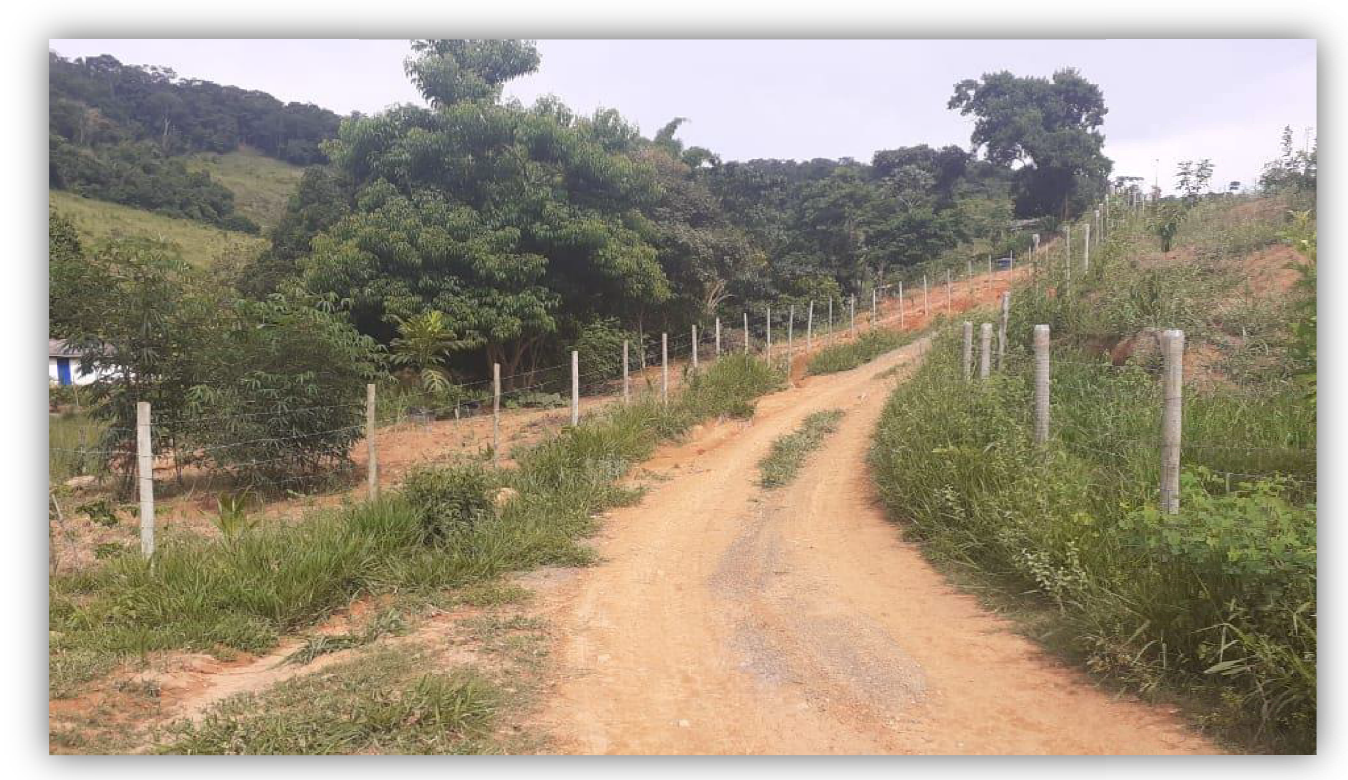

Figura 1

Fonte: (Autoria Própria, 2021).

Figura 2, defina-se projeto realizado no dialux que nos possibilita a simulação real dos efeitos de luz de forma interativa. Aqui visualizamos apenas alguns postes. O projeto final consiste em 26 postes com as distancias entre eles de 12 metros, assim atendo todas as regras das normas. (ABNT NBR 5101:2018). 


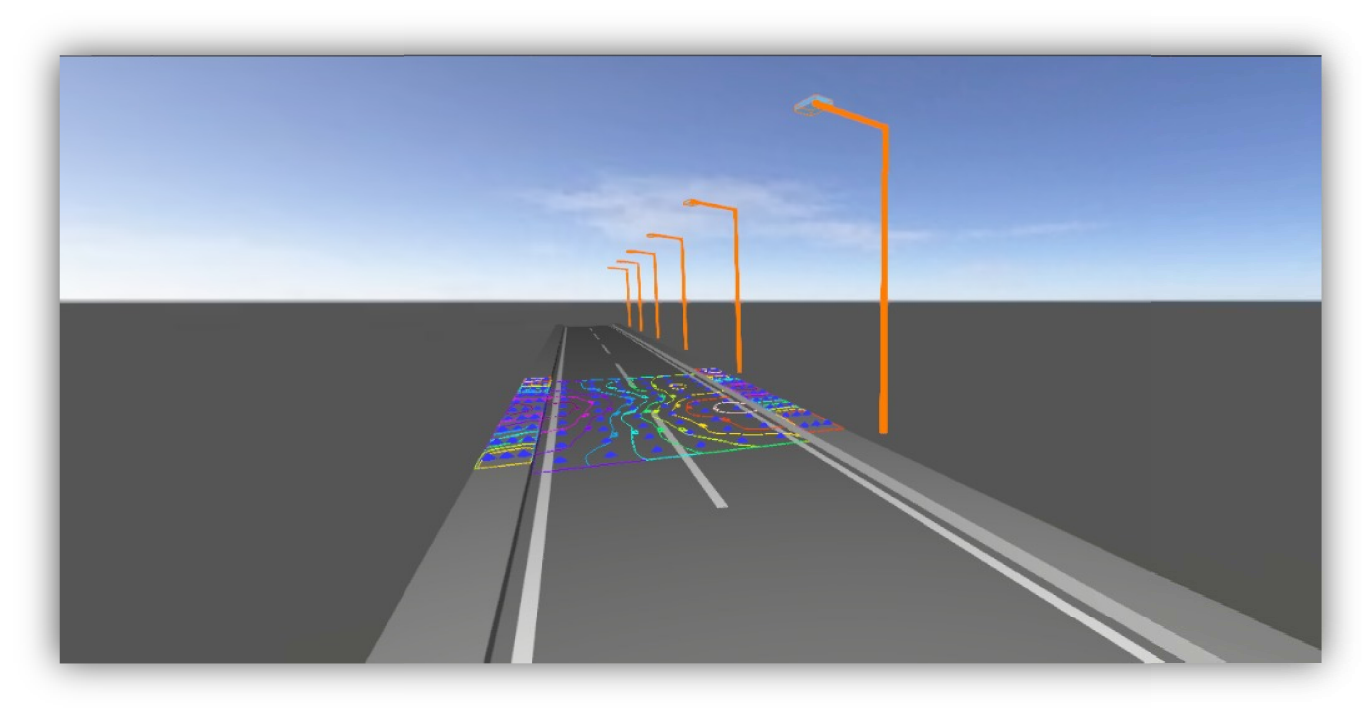

Imagem 2

Fonte: (Autoria Própria, 2021).

Através do desenvolvimento e planejamento do projeto para instalação de luminária autônoma eficiente. O forneciemnto de uma iluminação autônoma, consiste na instalção de um poste equipado com painel fotovoltaico e demais itens que funcionam de forma independe, sem a necessidade de um rede elétrica para alimentação desse poste. Durante o dia, os paineis fotovoltaicos convertem a energia solar em energia éltrica, que, por sua vez, é acumulada nas baterias que alimentam as luminarias durante a noite. Esses sistemas autônomos, podem ser uma alternativa com uma boa relação custo-benefício em locais distantes da rede elétrica. Outra vantegm desse tipo de sistema é o fato de ser imune á falta de energia (apagões). Com isso a ideia foi entregue satisfatoriamente com grande chance de sucesso, atendendo ao escopo de fornecimento com qualidade e segurança. A ideia de colocar as lâmpadas de LED abarca questões ambientais, econômicas e até de poluição visual uma vez que o LED se apresenta como alternativa com facho de luz bem direcionado, livre de metais pesados, com vida útil estendida, alta eficiência e flexibilidade na escolha de temperatura de cor e sendo assim pensamos em implantar 0 sistema fotovoltaico para trazer uma forma mais pratica de se alimentar essas lâmpadas. 


\section{Discussão}

Com a escassez de chuvas que o Brasil vem enfrentando nos últimos anos, a produção de energia pelas usinas hidrelétricas não tem conseguido atender a demanda energética do país. Com isso, usina solar fotovoltaica vem sendo utilizadas para que não haja falta de energia. A principal consequência disso é que os custos da energia elétrica no país estão cada vez mais elevados.

Esta experiência piloto permitirá realizar discussões de formas para incluir energia solar fotovoltaica como uma das opções de geração elétrica no planejamento do setor energético, para ambientes privados ou em zonas vulneráveis. Particularmente à discussão forma de utilização de lâmpadas de LED de alta eficiência em conjunto com os painéis fotovoltaico.

O sistema foi montado em um loteamento de chácaras, sendo uma experiência piloto permitirá realizar discussões de formas a incluir a energia solar fotovoltaico como uma das opções de geração elétrica no planejamento do setor energético brasileiro, tanto no ambiente urbano quanto rural.

\section{Conclusão}

Conclui-se que a energia solar merece destaque devido a sua disponibilidade e o seu potencial de transformação em energia térmica ou utilizando sistema de painéis fotovoltaicos serem convertida em energia elétrica, e que ao elaborar esse projeto vemos que ao implementar esse tipo de sistema aonde não a nenhum tipo de iluminação pública, traz uma forma sustentável de gerar e futuramente uma economia financeira. Mostrando a importância em utilizar Led's na iluminação, sendo alimentadas por um sistema de energia solar, possibilitando uma geração limpa e uma iluminação eficiente. Uma fonte inesgotável de energia como o sol não pode ser desprezada, porém a limitação em seu uso se torna um ponto fraco para o seu investimento, contudo, utilizando-a para sistemas que necessitam de pouca energia pode ser tornar viável. O projeto mostrou a possibilidade de ser realizar iluminação com 
sistemas de baixo consumo, podendo assim, reduzir aos poucos a necessidade da energia convencional.

\section{Referências:}

Altenhofer, Daniel, Linck- Estudo de Viabilidade de otimização de sistemas de iluminação pública: automação de luminárias. UERGS - Universidade Estadual do Rio Grande do Sul, Porto Alegre, 2021. Disponível em:<https://repositorio.uergs.edu.br/xmlui/bitstream/handle/123456789/1231/27 216_tcc_-_daniel_linck.pdf?sequence=-1\&isAllowed=y> Acesso em: 21 maio. $202 \overline{1}$

BAGLI, Fernanda de Lima. Estudo de Projeto de viabilidade para aquisição e instalação de luminária com lâmpadas de LED, alimentadas por células fotovoltaicas.2015. 100 f. Prudente Centro Universitário -ETIC 2015- Encontro de Iniciação Cientifica ISSN 21-768489. Disponível em: <http://intertemas.toledoprudente.edu.br/index.php/ETIC/article/view/4777>.

Acesso em 24/03/2021

Bakman, Igor Estudo de viabilidade financeira de um projeto de iluminação LED/Igor Bakman. - Rio de Janeiro: UFRJ/ Escola Politécnica/ Curso de Engenharia Elétrica, 2018 IX. Disponível em: http://www.monografias.poli.ufrj.br/monografias/monopoli10023321.pdf>. Acesso em 24/03/2021

BARBOSA, Leonardo. UMA AVALIAÇÃO DA TECNOLOGIA LED NA ILUMINAÇÃO PÚBLICA - Rio de Janeiro: UFRJ / Escola Politécnica, 2014/ Curso Engenharia Elétrica. Disponível em: http://www.monografias.poli.ufrj.br/monografias/monopoli10010665.pdf Acesso em 24/03/2021

FAGUNDES, PATRICIA.GÓES, HIROHUMI, ARMANDO TANIMOTO. TECNOLOGIAS E PARÂMETROS AMBIENTAIS PARA A ESCOLHA DE UMA PLACA GERADORA DE ENERGIA SOLAR FOTOVOLTAICA. Revista Scientia, v. 6, n, 1, p.34-61. Salvador, jan/abr. 2021. Disponível em: file://C:/Users/mla2/Downloads/9521-Texto\%20do\%20artigo-29387-1-1020210103.pdf. Acesso em: 11 abril. 2021.

GERALDO, Sandro A. S. EFICIÊNCIA ENERGÉTICA APLICADA A ILUMINAÇÃO. Trabalho de conclusão de curso (Bacharelado - Engenharia de Controle e Automação) - Universidade Federal de Ouro Preto, Universidade Federal de Ouro Preto - UFOP - Escola de Minas - Colegiado do curso de Engenharia de Controle e Automação - CECAU, 2017. Disponível em:<https://www.monografias.ufop.br/bitstream/35400000/964/1/MONOGRAFI A_Efici\%C3\%AAnciaEnerg\%C3\%A9ticaAplicada..pdf>. Acesso em 23/03/2021.

KIKUCHI, Jaime Yoshitoyo. Estudo de análise comparativa da eficiência de um sistema alimentado por células fotovoltaicas para utilização em luminárias do tipo LED com e sem etapas de conversão. 2014. $100 \mathrm{f}$. Trabalho de conclusão de curso (Bacharelado - Engenharia Elétrica) - Universidade Estadual Paulista, Faculdade de Engenharia de Guaratinguetá, 2014. Disponível em: <http://hdl.handle.net/11449/123061>. Acesso em 24/03/2021 
LIMA, A.A., MENEZES, N.P., SANTOS, S., AMORIM, B., THOMAZI, F., ZANELLA, F., HEILMANN, A., BURKARTER, E., DARTORA, C.A. Uma revisão dos princípios da conversão fotovoltaica de energia. Revista Brasileira de Ensino de Física, v. 42, São Paulo, out. 2020. Disponível em: https://bit.ly/34SWikK. Acesso em: 18 ago. 2020.

LIMA, A.A., MENEZES, N.P., SANTOS, S., AMORIM, B., THOMAZI, F., ZANELLA, F., HEILMANN, A., BURKARTER, E., DARTORA, C.A. Uma revisão dos princípios da conversão fotovoltaica de energia. Revista Brasileira de Ensino de Física, v. 42, São Paulo, out. 2020. Disponível em: https://bit.ly/34SWikK. Acesso em: 11 abril. 2021.

Poste, Galvanizado 7 Metros. Ferraço postes, 202 . Disponível em:https://www.ferracopostes.com.br/galvanizado/poste-galvanizado-7metros>.Acessoem 25 maio. 2021.

SAMPAIO, J.A., AMADO, R.S., MARQUES, P.S.G, SOARES, L.G.L. Silício Grau Solar - Uma Revisão das Tecnologias de Produção. CETEM - Centro de Tecnologia Mineral. Série Rochas e Minerais Industriais, n. 26, Rio de Janeiro, 2019. Disponível em: https://bityli.com/V27vm. Acesso em: 20 ago. 2020

Teodosio, Matheus, Gabriel Dantas- Informação de recurso solar para projetos de aproveitamento energético. UERGS -Universidade Federal de São Paulo, São $\quad$ Paulo, $2020 . \quad$ Disponível em:< https://repositorio.unifesp.br/bitstream/handle/11600/60247/TCC_MATHEUS_T EODOSIO_att.pdf?sequence=1\&isAllowed =y> .Acesso em: 21 maio. 2021

APÊNDICE A - Resultados Obtidos Através do DIAlux e Aterramento. Disponível:https://drive.google.com/file/d/12C4LMqbYQy9pCpqCVRr8zma0qQ PkLsuO/view.Fonte: Autoria Própria, 02 junho. 2021 